Highlights:

2

3 - A UHPLC/MS/MS method for N-nitrosamines quantification in water samples was

4 developed.

5 - A solid phase extraction procedure was proposed for analytes extraction.

6

7 - The proposed extraction procedure allows the extraction and purification of surface water 8 samples.

9

10 - Proposed method successfully applied to the detection of pollution in real water samples. 


\section{MEASUREMENT OF POLLUTION LEVELS OF N-NITROSO COMPOUNDS OF HEALTH CONCERN IN WATER USING ULTRA- PERFORMANCE LIQUID CHROMATOGRAPHY-TANDEM MASS SPECTROMETRY}

*Correspondig Authors:

Yassine Kadmi $^{\text {a,b*, Lidia Favier }}{ }^{\mathrm{a}, \mathrm{b}^{*}}$, Andrei Ionut Simion ${ }^{\mathrm{c}}$, Lacramioara Rusuc, Mariana Liliana Pacala ${ }^{\mathrm{d}}$, Dominique Wolbert ${ }^{\mathrm{a}, \mathrm{b}}$

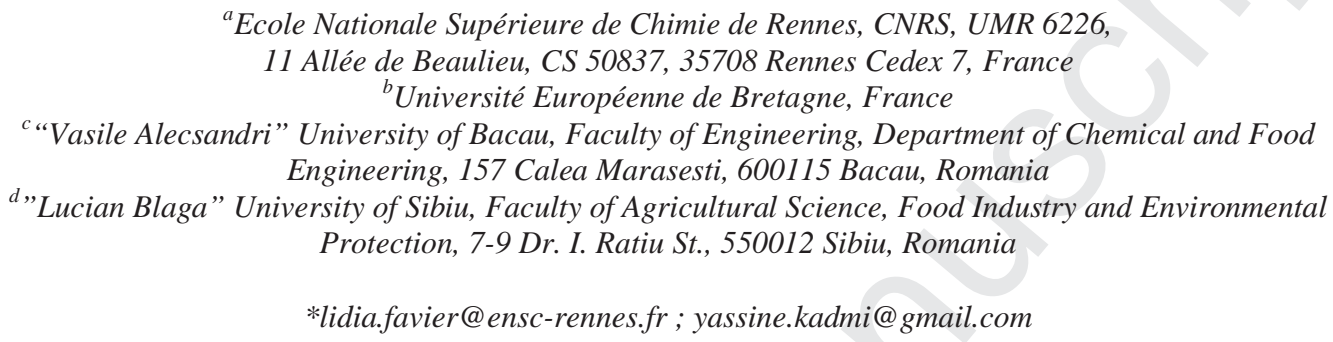

Dr. Lidia Favier, Associate Professor

Ecole Nationale Supérieure de Chimie de Rennes, CNRS, UMR 6226, Université Européenne de Bretagne, 11 Allée de Beaulieu CS 50837, 35708 Rennes Cedex 7, France.

E-mail: lidia.favier@ensc-rennes.fr

Dr. Yassine Kadmi

Ecole Nationale Supérieure de Chimie de Rennes, CNRS, UMR 6226, Université Européenne de Bretagne, 11 Allée de Beaulieu CS 50837, 35708 Rennes Cedex 7, France. 
Highlights:

2

3 - A UHPLC/MS/MS method for N-nitrosamines quantification in water samples was

4 developed.

5 - A solid phase extraction procedure was proposed for analytes extraction.

6

7 - The proposed extraction procedure allows the extraction and purification of surface water 8 samples.

9

10 - Proposed method successfully applied to the detection of pollution in real water samples.

11

12

13 


\section{Abstract}

2

This paper reports the development of a highly sensitive analytical method combining solid-phase extraction (SPE) with ultra-high performance liquid chromatography coupled with tandem mass spectrometry (UHPLC-MS/MS), for the monitoring of ultra-trace levels of N-nitrosamines in water samples.

Under optimized analytical conditions, chromatographic separation was performed in three minutes, in isocratic mode, using an Acquity UHPLC C18 column and a mobile phase consisting of acetonitrile, water, and formic acid $(60: 40: 0.1, \mathrm{v} / \mathrm{v} / \mathrm{v})$ at a flow rate of $0.4 \mathrm{~mL} \mathrm{~min}^{-1}$. Electrospray ionization tandem interface was employed prior to mass spectrometric detection. Good linearity $\left(\mathrm{R}^{2} \geq 0.9987\right)$ and low limits of detection $\left(0.04\right.$ to $\left.0.4 \mathrm{ng} \mathrm{L^{-1 }}\right)$ and quantification (0.1-1.2 $\mathrm{ng} \mathrm{L}^{-1}$ ) were obtained. The extraction recoveries ranged from $98 \pm 1 \%$ to $100 \pm 1 \%$ and the relative standard deviations were less than $1.53 \%$. The matrix effect was between $98 \pm 2$ and $100 \pm 1 \%$.

The obtained results clearly demonstrate that the developed method is accurate and highly sensitive for the simultaneous determination of N-nitroso-n-propylamine, Nnitrosomorpholine, N-nitrosomethylethylamine and $\mathrm{N}$-nitrosodimethylamine at ultra-trace levels $\left(\mathrm{ng} \mathrm{L}^{-1}\right)$ in different types of water samples. Therefore, this method can be a useful analytical tool for future toxicological, water quality surveillance studies and for the investigation of drinking water quality.

Keywords: water quality; N-nitrosamines; solid phase extraction; ultra-high liquid chromatography-tandem mass spectrometry 


\section{Introduction}

(1)

.

(s)

$$
\text { issue, due to their mutagenic and carcinogenic effects at ultra trace levels (ng } \left.\mathrm{L}^{-1}\right) \text {. As a }
$$
consequence, in recent years, this class of molecules has received an increased interest from environmental and analytical chemists. They are generally produced during different industrial processes such as cosmetics, metal casting, leather tanning, food (beverages and meats) or during the rubber or dyes manufacturing. Thus, these kinds of applications commonly lead to wastewater and groundwater contamination. For example, high concentrations $\left(2 \mathrm{mg} \mathrm{L}^{-1}\right)$ of N-nitrosodimethylamine (NDMA) were found in Ontario, in downstream industrial water of a tyre factory (Mitch et al., 2003). More recently, another study carried out in Switzerland reported the presence of N-nitrosamines in the influents of an urban wastewater treatment plant at a concentration level ranging from 5 to $25 \mathrm{ng} \mathrm{L}^{-1}$ (Krauss et al., 2009; Sedlak et al., 2005).

Moreover, it was found that drinking water disinfection processes with chlorine, monochloramine, chlorine dioxide, and ozone generally lead to the formation of these compounds in treated water, by the reaction between disinfectant and the nitrogen containing organic matter (Andrzejewski et al., 2008; Kadmi et al., 2015a, 2015b; Schreiber and Mitch, 2005).

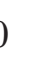

1
different sites situated in North America and Canada. Other studies confirmed their presence in drinking water (Richardson, 2009; Zhao et al., 2006) and of NDMA, NMOR in surface water (Kosaka et al., 2010; Zhao et al., 2008).

4

5
(DBPs) which have been recently identified in drinking water. NAms are alkylating agents characterized by the presence of the N-nitroso group and may be aliphatic or ring structures. Different studies reported that these molecules are significantly more toxic than the regulated DBPs (Oya et al., 2008).

In response to their suspected adverse risks on human health, different guidelines have been implemented in United States and Canada for these molecules and more particularly, for 1 NDMA, which is one of the most detected. However, in the European Community these 2 molecules are not yet regulated. Indeed, NAms are not listed in the Drinking Water Directive 3 (Council Directive 98/93/EC), but a few European Union (EU) member states have regulated 34 their presence in drinking water. Provisional standard values were proposed only in 
1 Netherlands and in Germany for NDMA and N-nitrosomorpholine (NMOR) (Kadmi et al., 2 2014; Planas et al., 2008). In addition, the French government proposed recently the addition 3 of NDMA in the EU Directive for drinking water, and a guideline value of $100 \mathrm{ng} \mathrm{L}^{-1}$, according with the guideline of the World Health Organization (WHO, 2011).

Therefore, in the light of new regulations at European level and for water quality monitoring purposes it is of great interest to develop fast, sensitive and environmentally friendly analytical methods for the monitoring of trace and ultra-trace levels of $\mathrm{N}$ nitrosamines in water samples. The major challenge in the determination of these molecules is to attain the high sensitivity required for the quantification of trace levels in environmental samples. environmental samples in the range of nanogram NAms per liter. Due to the low concentration level of these compounds in the aquatic environment and in drinking water an extraction and pre-concentration step of analytes is generally required.

$\mathrm{N}$-nitrosamines are polar compounds with low molecular weights $\left(<200 \mathrm{~g} \mathrm{~mol}^{-1}\right)$, usually water soluble and have low octanol/water $\left(\mathrm{K}_{\mathrm{ow}}\right)$ partition coefficients. Consequently, they are difficult to extract with organic solvents or to remove by adsorption.

Several selective analytical techniques have been reported for the quantification of NAms. The analytical strategies currently used mainly consists of two steps, i.e., analysis by gas chromatography (GC) or liquid chromatography (LC) and an extraction/concentration procedure for the concentration of analytes. The NAms have been determined in water samples by using GC coupled with different types of detectors, such as gas chromatographycoupled with mass spectrometry (GC/MS) (Huang et al., 2013; Reyes-Contreras et al., 2012; Ventana and Ruiz, 2006) and gas chromatography-tandem mass spectrometry (GC/MS/MS) (Llop et al., 2012; McDonald et al., 2012). However, these methods are limited to the analysis of volatile and thermally stable compounds. Other studies focused on the determination and quantification of NAms by liquid chromatography using a fluorescence detector (Cha et al., 2006) and high pressure liquid chromatography-tandem mass spectrometry (HPLC/MS/MS) (Cheng et al., 2011; Zhao et al., 2006).

The aim of the present work was to develop a rapid and robust analytical SPEUHPLC-MS/MS protocol for the simultaneous quantification of $\mathrm{N}$-nitrosamines in water samples. The developed analytical procedure has been selected in order to attain the selectivity, sensitivity and sample throughput which is needed for the quantification of these molecules in water samples. Based on occurrence and toxicity data, the N-nitrosamines 
1 selected for this work were: N-nitroso-n-propylamine (NDPA), N-nitrosomorpholine

2 (NMOR), N-nitrosomethylethylamine (NMEA) and N-nitrosodimethylamine (NDMA).

The study of the performance of the developed method was carried out in terms of method detection limits (MDL), method of quantification limits (MQL), linearity, extraction recovery and matrix effect.

The developed analytical method was then applied to real water samples (surface water and treated water samples from public water system) collected from different locations in Brittany region (France) in order to measure the pollution levels. Since these molecules are usually not considered in routine monitoring programs in Europe, and especially in France, information about the contamination level with these emerging DBPs is very limited.

\section{Materials and methods}

\subsection{Chemicals, standards and preparation of stock solutions}

Individual standard solutions (2000 $\mathrm{mg} \mathrm{L}^{-1}$ in methanol) of $\mathrm{N}$-nitrosamines were purchased from LGC Standards (Wesel, Germany). The main physico-chemical characteristics of the studied molecules as well as their toxicity are shown in Table 1.

\section{Table 1}

Acetonitrile (LC-MS grade) and formic acid (>95\%) were obtained from J.T. Baker (Deventer, Netherlands). Methanol and GC-grade dichloromethane were purchased from Fischer Scientific-Bioblock (Illkirch, France). Acetic acid (100\%) was supplied by Acros Organics (Noisy-le-Grand, France). All reagents used in this work were of the highest analytical grade (suitable for trace analysis). The ultrapure water used for the preparation of the samples was obtained from an Elga Option-Q DV-25 system (Antony, France). Nitrogen for drying (99.99\% purity) was from Air Liquid (France).

A standard mix stock solution of $100 \mathrm{mg} \mathrm{L}^{-1}$ containing the target analytes (NDPA, NMOR, NMEA and NDMA) in methanol was prepared and stored in a freezer at $-20^{\circ} \mathrm{C}$ for up to three months. Working solutions were freshly prepared prior to UHPLC/MS/MS analysis with 60: $40(\mathrm{v} / \mathrm{v})$ acetonitrile/ultrapure water at the desired concentration by appropriate dilution of the stock standard solution. 
Cartridges used for off-line SPE analytes extraction were Sep-Pak Plus ${ }^{\circledR}$ AC-2 cartridges (400 mg, $85 \mu \mathrm{m}$ ) purchased from (Waters, Guyancourt, France).

Safety precautions were taken when handling N-nitrosamines because of their carcinogenic risks for humans and animals. The disposal of the resulted waste followed a proper safety procedure.

\subsection{Samples collection}

Water samples were directly collected from different surface and drinking water from different locations situated in Brittany region (France) in June-July and October-November 2014 and in June-July 2015. Sample sites can be showed in Fig. 1.

Water samples were collected in pre-cleaned amber glass bottles (4-L) with Teflon lined caps to ensure sample integrity. Before sampling bottles were rinsed several times with the same water samples in order to avoid internal contamination. In order to remove suspended particles water samples were vacuum filtered through cellulose membrane $(0.45 \mu \mathrm{m}$; Sartorius, Germany) and stored at $4^{\circ} \mathrm{C}$ under light protection until analysis (within one week of collection). No additives were placed in the samples to prevent their contamination.

\section{Figure 1}

\subsection{Methods}

\subsubsection{Sample concentration and clean-up}

An SPE-off line method was performed and developed in order to extract, purify and concentrate the water samples. A 12-port position Visiprep SPE vacuum manifold obtained from Supelco (Bellefonte, PA, USA) was used. Several sorbents were evaluated for the extraction of analytes. Sep-Pak Plus ${ }^{\circledR A C}-2$ cartridges ( $400 \mathrm{mg}, 85 \mu \mathrm{m}$; Waters, Guyancourt, France) showed the best extraction recoveries for all considered molecules, even for hydrophilic molecules such as NDMA and NMOR.

Briefly, cartridges were initially pre-conditioned with $8 \mathrm{~mL}$ of methanol followed by 8 $\mathrm{mL}$ of dichloromethane, $8 \mathrm{~mL}$ of acetonitrile and $8 \mathrm{~mL}$ of ultrapure water. A sample volume of $250 \mathrm{~mL}$ was loaded with a light vacuum on the cartridge and a flow rate of approximately $3 \mathrm{~mL} \min ^{-1}$. The sorbent was then rinsed with $5 \mathrm{~mL}$ of ultrapure water 
1 acidified at $\mathrm{pH} 2$ with acetic acid. Analytes adsorbed on SPE cartridges were eluted successively with $6 \mathrm{~mL}$ of dichloromethane, $4 \mathrm{~mL}$ of acetonitrile, and $2 \mathrm{~mL}$ of methanol at a

3 flow rate ranging from 2 to $3 \mathrm{~mL} \mathrm{~min}$. . Cartridges were air-dried for few minutes to remove 4 the water drops. After the extraction step, the elution solvent was collected in conical graduated glass tube Pyrex ${ }^{\circledR}$ (VWR, Fontenay-sous-Bois, France).

Eluates were then concentrated by evaporation under a high-purity and moderate nitrogen flow in an N-Evap evaporation system (Organomation, Berlin, MA, USA) to a final volume of $0.1 \mathrm{~mL}$ (concentration factor of 2.500). Extracts were reconstituted with acetonitrile/ultrapure water $(60: 40, \mathrm{v} / \mathrm{v})$, transferred to an injection vial and stored at $4{ }^{\circ} \mathrm{C}$ until further analysis.

\subsubsection{Instrumentation}

The target compounds were separated by a Waters Acquity UHPLC H-Class system, containing a binary pump, an auto-sampler and a thermostated column compartment (Waters, Saint-Quentin en Yvelines, France). Chromatographic separation of N-nitrosamines was carried out on Ethylene Bridged Hybrid (BEH) C18 column $(100 \mathrm{~mm} \times 2.1 \mathrm{~mm}, 1.7 \mu \mathrm{m})$ from Waters. The used column is packed with a C18 reverse phase bounded to an ethylenebridged hybrid (BEH) substrate. In the chromatographic system, column was protected by an in-line filter unit purchased from Waters (Saint-Quentin en Yvelines, France). The analytical column compartment was maintained at $45^{\circ} \mathrm{C}$. The auto-sampler was conditioned at $5^{\circ} \mathrm{C}$. For the optimization of the chromatographic analysis and MS/MS characterization, standard solutions of each $\mathrm{N}$-nitrosamine in mobile phase were used.

Isocratic elution was carried out with LC-MS grade acetonitrile/ultrapure water mix $(60: 40, \mathrm{v} / \mathrm{v})$ with added $0.1 \%(\mathrm{v} / \mathrm{v})$ formic acid. The flow rate was $0.4 \mathrm{~mL} \mathrm{~min}{ }^{-1}$, and the injection volume was $5 \mu \mathrm{L}$.

Tandem mass spectrometry (MS/MS) determination was performed on a Quattro Premier Triple Quadrupole Mass Spectrometer (Waters, France) equipped with an electrospray ionization source (ESI). ESI experiments were designed in positive and negative ionization mode (ESI) to determine the optimal MS/MS detection conditions. Quantitative analysis was carried out in Multiple-Reaction Monitoring (MRM) mode. In addition, the cone voltage and the collision energy were optimized in order to achieve the best sensitivity.

The optimal MS/MS conditions selected for the analysis of target compounds were: capillary voltage $3 \mathrm{kV}$; cone voltage $40 \mathrm{~V}$; source temperature $120^{\circ} \mathrm{C}$ and desolvation 
1 temperature $350^{\circ} \mathrm{C}$. The considered cone and desolvation gas flows were 75 and $750 \mathrm{~L} \mathrm{~h}^{-1}$, 2 respectively. High purity argon (99.99\% purity, Air Liquid, Paris, France) was employed as 3 collision gas at a flow rate of $0.12 \mathrm{~mL} \mathrm{~min}^{-1}$. Dry nitrogen used as desolvation, nebulization and cone gas was produced by a nitrogen generator (Peak Scientific, Inchinann, UK). The argon pressure used in the collision cell was $3.52 \times 10^{-3}$ mbar. The analytical system control and data acquisition were processed using Masslynx software, version 4.1 (Waters, SaintQuentin en Yvelines, France).

\subsection{Quality parameters}

The ultra-high performance liquid chromatography tandem mass spectrometry method was evaluated in terms of linearity, instrumental limits of detection (IDL) and quantification (IQL), method detection (MDL) and quantification limits (MQL), precision; but also through the extraction recovery on the whole extraction protocol and matrix effects. To evaluate the practical applicability of the developed method, analytical quality parameters were investigated using spiked water samples.

Linearity of the instrumental method was investigated for all analytes, from the calibration curves, at seven calibration levels ranging from 0.1 to $100 \mu \mathrm{g} \mathrm{\textrm {L } ^ { - 1 }}$. Standard solutions were prepared by spiking calculated volumes of ultrapure water. The standard calibration curves were generated by least squares linear regression. This method was used to determine the slope, intercept, and correlation coefficient $\left(\mathrm{R}^{2}\right)$ of the calibration equation. The applied calibration model for all curves was $y=a x+b$ (weighting $1 / x$ ), where $y$ was the peak area, $x$ was the concentration of the compound, $a=$ the slope of the curve, and $b=$ the intercept.

The sensitivity of the developed instrumental method was determined in terms of instrumental detection and quantification limits. IDL and IQL were defined as the concentration which gave a signal-to noise ratio $(\mathrm{S} / \mathrm{N})$ above 3 and 10 , respectively. The noise was measured from six independent analyses.

The linearity of the analytical method was determined by passing the entire extraction and clean-up method (SPE) on ultrapure and surface water samples spiked with the selected compounds at concentrations ranging from 0.04 to $40 \mathrm{ng} \mathrm{L}^{-1}$ considering a pre-concentration factor of 2500. These samples were used to build the sample calibration curves (SCC). Moreover, they are used to determine the MDL and MQL defined as the lowest concentration which gave an $\mathrm{S} / \mathrm{N}$ of 3 and an $\mathrm{S} / \mathrm{N}$ above 10 , respectively. These samples were also used to 
1 calculate the repeatability (intra-day precision) of the method. It was determined for the 2 lowest level of concentration $\left(0.4 \mathrm{ng} \mathrm{L}^{-1}\right)$ by analyzing the same spiked sample in six 3 replicates within a single day and results were expressed in terms of relative standard 4 deviation (RSD).

For the SPE extraction methodology of N-nitrosamines, SPE recoveries (R, \%) were 6 determined quantitatively at different concentration levels. These recovery studies permitted 7 the evaluation of the efficiency of the proposed SPE method. They were investigated by 8 analyzing water samples at three concentration levels $\left(0.4,4\right.$ and $40 \mathrm{ng} \mathrm{L}^{-1}$, respectively) 9 spiked before and after extraction and clean-up procedure with appropriate amounts of the mix N-nitrosamines standard solution. SPE recoveries were calculated as the ratio between the resulting peak areas of the both extracted and non-extracted samples.

Matrix effect $(\mathrm{ME}=\mathrm{C} / \mathrm{D})$ was determined for each analyte and sample as previously described by Matuszewski et al. (2003). It was calculated as the ratio between responses (peak areas) obtained in the presence of the matrix (C: samples spiked after extraction) to the responses (peak areas) obtained in absence of the matrix (D: pure standard solution). This method of calculation was used in many studies to evaluate the matrix effect in environmental and biological samples. In this work, the matrix effect was evaluated by using real water samples and was expressed as percentage. It will be noticed that, the used sample was first checked to verify that no analyte was detected in the matrix.

\section{Results and discussions} simultaneous extraction and analysis of N-nitrosamines in water samples. In the light of the lack of rapid, sensitive and robust methods for the analysis of these molecules in water samples, the methodology proposed in this work has been focused especially on the determination of these molecules at concentration levels relevant for environmental water samples. As indicated above, the selection on the target molecules was mainly based on their toxicity and occurrence in environmental waters. 


\subsection{Optimization of the MS/MS detection conditions}

4

MS/MS detection conditions. Parameters of the mass spectrometer were obtained by direct infusion of a standard solution of each analyte $\left(1 \mathrm{mg} \mathrm{L}^{-1}\right)$ into the source of the mass spectrometer. For analyte infusion a fixed flow rate of $10 \mu \mathrm{L} \mathrm{min}^{-1}$ was used.

For the ionization of the target analytes, electrospray ionization (ESI) and atmospheric pressure ionization (APCI) modes with positive or negative ionization were investigated. Obtained data clearly showed that the optimal analytes responses were observed in positive ionization mode due to its high sensitivity (data not shown). Thus, a positive ionization mode $\left(\mathrm{ESI}^{+}\right)$combined with multiple reaction monitoring (MRM) was considered in this study for further quantification purposes.

3
were also studied and the optimum operating conditions are presented in Table 2. The effects of desolvatation gas flow (rate 600-900 $\left.\mathrm{L} \mathrm{h}^{-1}\right)$ and cone gas flow rate $\left(0-100 \mathrm{~L} \mathrm{~h}^{-1}\right)$ were analyzed. No significant influence on the signal of precursor ion was observed. These results are similar with the ones previously reported by Mourao Rodrigues et al. (2006) for the analysis of pesticides. For further analytical purposes the considered values for desolvatation gas flow and cone gas flow were $750 \mathrm{~L} \mathrm{~h}^{-1}$ and $75 \mathrm{~L} \mathrm{~h}^{-1}$, respectively as recommended by the manufacturer. In addition, the mobile phase composition was evaluated because this parameter is crucial for the separation and detection of target molecules. It was found that formic acid increases the ionization of all considered analytes. energy and cone voltage) were evaluated for best response under positive mode conditions $\left(\mathrm{ESI}^{+}\right)$by direct infusion in the source of a standard solution of each compound $\left(1 \mathrm{mg} \mathrm{L}{ }^{-1}\right)$ into the mass spectrometer. For these tests the cone voltage in the mass spectrometer scan mode was varied from 10 to $35 \mathrm{eV}$ and the collision energy from 9 to $20 \mathrm{eV}$.

In this study, two sensitive MRM transitions were considered for each N-nitrosamine according to the requirements regarding mass spectrometric confirmation defined by the EU Commission Decision 2002/657/EC. Indeed, two transitions have to be recorded for each analyte in order to have a sufficient number of identification points for a suitable 
confirmation. Hence, in this work, the peak area of the most intense transition was used for quantitative purposes and the less intense one for confirmation. The cone voltage and the collision energy were also investigated. The optimized MS/MS transitions as well as specific cone voltage, collision energy, are presented in Table 3.

\section{Table 3}

\subsection{Optimization of separation conditions}

Separation and ionization of analytes is generally affected by the composition of the mobile phase. Thus, in this work, the influence of mobile phase composition and mobile phase additives on the separation of the target molecules was studied. Different compositions of the mobile phase (i.e., acetonitrile/water and methanol/water) modified with acetic acid, or formic acid $(0.05,0.1,0.2$, and $0.3 \%)$ were investigated in order to obtain an efficient separation of N-nitrosamines using the BEH C18 column. An important increase in the measured signal intensity was observed for the four analytes using acetonitrile/water (60:40, $\mathrm{v} / \mathrm{v}$ ), modified with formic acid. In addition, the measured responses were higher than those obtained in both mobile phases containing acetic acid (data not shown). Indeed, the use of formic acid improves the ionization efficiency. Obtained data showed that a very low concentration of formic acid lead to a lack of protons while a high concentration conduct to a ion suppression. Thus, both conditions would reduce the analytical sensitivity (data not shown). Therefore, $0.1 \%$ of formic acid was chosen as additive for the mobile phase in this work.

The influence of column temperature and flow rate was also investigated. Column temperatures from $35^{\circ} \mathrm{C}$ to $50^{\circ} \mathrm{C}$ were tested, and $45^{\circ} \mathrm{C}$ was selected as the working temperature. Flow rates from 0.2 to $0.5 \mathrm{~mL} \mathrm{~min}^{-1}$ were assayed, and the obtained data indicated that a flow rate of $0.4 \mathrm{~mL} \mathrm{~min}^{-1}$ significantly improves the resolution, peak shape, intensity of the response, and retention times. Under optimized analytical conditions all the analytes were separated with high sensitivity and selectivity within a run time of three minutes.

\subsection{Method performance}


The performance of the developed analytical method was investigated in terms of recovery, linearity, limits of detection and quantification. The main evaluated quality parameters were indicated in Table 4 and Table 5.

\subsubsection{Recovery}

6

To overcome the drawback of extraction methods based on LLE some studies focused their attention on the extraction of these molecules by solid phase extraction because, this technique generally needs shorter processing times and less volumes of organic solvents. SPE methods use different types of sorbents for the extraction of specific N-nitrosamines from aqueous samples (Charrois et al., 2004; Cheng et al., 2006). However, several studies in literature reported extraction recoveries below 50\% and noticed the improvement in SPE procedure in order to attain lower quantification limits.

In the light of these considerations, a pre-concentration methodology based on solid phase extraction was developed in this work. SPE experiments were carried out after the optimization of UHPLC/MS/MS conditions. The optimization of the extraction process was performed in order to attain excellent recoveries for all target molecules in a single extraction step. The optimized conditions used in this work were previously described (Materials and methods section).

The SPE extraction recoveries were determined by extracting ultrapure water samples

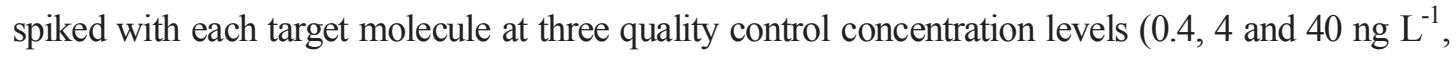


1 respectively). Six different sets of extractions $(n=6)$ for each sample were carried out.

2 Extracted samples were then analyzed by using the developed UHPLC/MS/MS method.

3 Extraction recoveries were obtained by comparing peak areas of the analytes obtained from 4 water fortified before extraction to those fortified after extraction.

As shown in Table 4, high mean recoveries were obtained for the considered analytes (between $98 \pm 1 \%$ and $100 \pm 1 \%$ ). Among the target molecules, at the spiked level of $40 \mathrm{ng} \mathrm{L}{ }^{-1}$, NMOR showed the highest recovery $(100 \pm 1 \%)$. This value is higher than the one reported by Zhao et al. (2006) for NMOR in spiked water samples for the same level of concentration. For their SPE methodology a mean recovery of $65 \%$ was obtained. For NDMA, MNEA and NDPA low extraction recoveries were reported (between 75 and $82 \%$ ).

\section{Table 4}

For NMOR, recoveries in the same range of magnitude were obtained by Jurado-Sanchez et al. (2009) using LiChronut and Oasis HLB cartridges.

In this study for NDMA, the calculated recoveries were higher than $98 \%$ (Table 4). Similar recoveries were obtained by other authors (Charois et al., 2004; Plumlee et al., 2008). Moreover, the values of the calculated relative standard deviations (RSD) were below $1.53 \%$ for all analytes and all control concentrations tested (Table 4).

\subsubsection{Linearity}

For N-nitrosamines studied in this work the calibration curves were linear over the considered concentration range. It will be noticed that, for linearity studies all samples were analyzed in triplicate. For instrumental calibration curves the tests were carried out without organic interfering species (ultrapure water). They were determined by using serial dilutions of standard solutions containing the selected analytes and were established by plotting peak areas against the analyte concentration. Obtained data showed good correlation mean coefficients for all N-nitrosamines. The calculated values are between 0.9987 and 0.9992 (Table 5). The lower correlation coefficient was obtained for NDMA and the higher for NDPA.

\section{Table 5}


1 As previously stated, sample calibration curves were also studied. They were determined from

2 the sample analysis in a given matrix, surface water samples spiked with selected analytes at

3 the same concentrations with the ones considered for instrumental calibration curves. For these assays blanks were periodically run to confirm the absence of any contamination. The calculated mean correlation coefficients were lower (between 0.9962 and 0.9983 ) than the ones obtained in spiked ultrapure water. All the obtained results for ICC and SCC were considered as satisfactory. Indeed, the linearity was considered as satisfactory when the $\mathrm{R}^{2}$

8 was $>0.99$.

\subsubsection{Matrix effect}

One of the major drawbacks of electrospray mass spectrometry is that the ionization source is highly sensitive to co-extracted matrix components. The mechanism and the origin of the matrix effect is not fully understood but it may originate from the competition between an analyte and the co-eluting, undetected matrix components which reacts with primary ions formed in the LC-MS/MS interface (Matuszewski et al., 2003; Kadmi et al., 2016).

Matrix effects can be highly variable, difficult to control or predict, and analyte specific (Chambers et al., 2007). Indeed, the presence of matrix components may lead to suppression (decrease in analyte ionization) or enhancement of the analyte response (ion enhancement) due to co-eluting matrix constituents affecting the detection capability, repeatability and accuracy of the assay (Bijlsma et al., 2009). Hence, such phenomenon severely affects the quantification of the analyte by electrospray mass spectrometry (Antignac et al., 2005; Caban et al., 2012). Therefore, the elimination of such effect is critical in the development of reliable analytical methods. Ignoring such phenomena may adversely affect the reliability of determination of analyte concentrations.

As previously stated, if unseen, undetected, endogenous compounds present in real water samples co-elute with the target molecules, they may affect the ionization efficiency of analytes leading to the increase or decrease in their MS response. In most cases it is impossible to completely eliminate the matrix effect.

Several action levels are proposed in literature to minimize their consequences in the final determination allowing obtaining accurate and reliable LC/MS/MS data. They include optimization of sample preparation to remove interfering compounds, changing chromatographic parameters to avoid the co-elution phenomenon, and changing MS conditions to reduce the occurrence of the matrix effect in the ion source (Chambers et al., 
1 2007; Van Eckhaut et al., 2009). However, the most direct means to obtain maximum 2 sensitivity and signal reproducibility is through reduction of matrix components prior to the 3 LC-MS/MS analysis by applying a selective extraction and improved sample clean-up methodology (Gomez et al., 2006). Such approach will limit the presence of interfering compounds in the final extract and will definitively overcome the problem of ion suppression. Numerous authors demonstrated the evidence of this approach. Other studies indicated that it is not a universal strategy but only solutions case by case for each analyte/matrix combination

8 (Antignac et al., 2005).

Thus, in this work the matrix effect of the optimized SPE-UHPLC/MS/MS analytical method was also investigated. It was evaluated by performing matrix effect experiments with different river water samples (collected in summer or in winter 2014) spiked with the target molecules at $0.4 \mathrm{ng} \mathrm{L}^{-1}$. They were performed in six replicates $(\mathrm{n}=6)$ for each analyte to assess the variability of instrumental response. Chromatographic peak areas (responses) of each analyte from the spiked after extraction samples were compared to those obtained from the standard solution at the same level of concentration $\left(0.4 \mathrm{ng} \mathrm{L}^{-1}\right)$ and the matrix effect was calculated as described above (Section 2.4). The obtained data in spiked river water samples collected in summer are shown in Table 5. For the selected analytes the determined matrix effects and the corresponding relative standard deviations were between $98 \pm 2$ and $100 \pm 1 \%$. These data demonstrated the absence of a detectable matrix effect for the considered analytes determined in ground water extracts. The obtained data were very similar with the ones measured in ultrapure water samples spiked for the same level of concentration. They are consistent to the ones obtained using spiked surface water samples collected in winter, for which, higher concentration in natural organic matter are expected (data not shown). In addition, it will be noticed that preliminary tests were carried out with river water samples spiked with the target molecules and their corresponding blank samples and the obtained data showed that the blank samples were free from interfering compounds (data not shown).

The satisfactory results (ME close to 100\%) obtained in different aqueous matrices clearly indicate no significant effects from the matrix composition of the environmental water samples. The sample pretreatment procedure (clean-up and pre-concentration) developed in this work efficiently reduced the amount of the co-extracted substances. The obtained results indicated that the analytical procedure (SPE-UHPLC/MS/MS) developed in this study allows to a reliable quantification of the target molecules in real water samples. They suggest that, the matrix effect have a minimal influence on the results of the proposed method. These results are quite similar to the ones reported previously, by Reyes-Contreras et al. (2012), 
1 Kadmi et al. (2014) and Kadmi et al. (2015c). In their work, Hung et al. (2010) also reported 2 that the complicated natural water matrix did not affect the performance of the SPME$3 \mathrm{GC} / \mathrm{MS} / \mathrm{MS}$ method developed for the trace analysis of N-nitrosamines. At contrary, the matrix effect appears as significant in the case of the analysis of NDMA in wastewater samples because of the high organic matter concentrations. For this kind of matrix, it was suggested to use an internal standard to eliminate analytical errors (instrumental and extraction recovery) caused by the matrix effect for the quantification of NDMA at low concentration levels (Topuz et al., 2012). However, the use of isotopically labeled internal standards, is expensive and they are not always commercially available for the analysis of molecules of interest.

For the analysis of drinking water samples, supplementary recovery tests may be necessary to be conducted because, chlorinated water includes residual chlorine that could affect the extraction recovery of analytes. Under these conditions, sodium thiosulfate must be added to reduce residual chlorine in chlorinated water samples (Pepich et al., 2004). Indeed, it is well-known that sodium thiosulphate acts as a reducing agent and it is suitable for the reduction of residual chlorine in water, preventing the chlorine interference in the analysis and extraction of analytes (Guerra Simões et al., 2007).

\subsubsection{Limits of detection and quantification}

As stated previously, the instrumental limits of detection and quantification (IDL and IQL) of the proposed method were calculated based on a signal to noise ratio $(\mathrm{S} / \mathrm{N})$ of 3 and 10 , respectively. The determined IDLs and IQLs ranged from $0.1 \mu \mathrm{g} \mathrm{L}^{-1}$ (for NMOR) to $1 \mu \mathrm{g}$ $\mathrm{L}^{-1}$ (for NDPA) and from $0.25 \mu \mathrm{g} \mathrm{L}^{-1}$ (NMOR) to $3 \mu \mathrm{g} \mathrm{L}^{-1}$ (for NDPA), respectively. For these parameters the lowest values were obtained for NDMA and NMOR (Table 6).

\section{Table 6}

The calculated MDLs of the selected N-nitrosamines for the SPE-UHPLC/MS/MS method were in the 0.1 to $0.4 \mathrm{ng} \mathrm{L}^{-1}$ range (except $0.04 \mathrm{ng} \mathrm{L}^{-1}$ for NMOR). It should be pointed out that, the excellent method detection and quantification limits obtained in this study make possible the analysis of N-nitrosamines at ultra-trace levels. Similar results were reported by Asami et al. (2009) for NDMA by using an SPE-UHPLC/MS/MS and by 
1 Kadmi et al. (2014) for NMEA. The obtained results, are better than those reported by Grebel

2 et al. (2006) using a SPME-GC/NCD methodology which are in the range of 57-193 $\mathrm{ng} \mathrm{L}^{-1}$.

3 A low method detection limit was also reported using a GC/LRMS technique. Templeton and

4 Chen (2010) developed an SPE with Ambersorb 484 and GC/LRMS methodology for the

5 analysis of N-nitrosamines with a MDL ranging from 0.9 to $4.4 \mathrm{ng} \mathrm{L}^{-1}$. Charois el al. (2004)

6 reported similar results by using GC/LRMS-PCI (ammonia positive chemical ionization) and

7 SPE with Ambersorb 572 and LiChronut EN as sorbents.

8 On the other hand, the California Department of Public Health set a notification level

9 for NDMA at $10 \mathrm{ng} \mathrm{L}^{-1}$ for drinking water. The obtained MDL for this molecule using the SPE-UHPLC/MS/MS method developed in this work is below this notification level. This suggests that the proposed analytical methodology can be considered as an interesting tool for the monitoring NDMA in drinking water samples. For NMOR and NDMA the results revealed that the MDL are much lower than the provisional standard values proposed in Netherlands and Germany (Planas et al., 2008). NMOR is considered to be less toxic compared to NDMA. Consequently, until now, any notification has been set for this Nnitrosamine in drinking water.

The overall results presented in this study demonstrate the analytical performance and sensitivity of the developed method. Indeed, the proposed SPE-UHPLC/MS/MS analytical strategy allow quantification limits in the ultra-trace range $\left(\mathrm{ng} \mathrm{L}^{-1}\right)$ and an enrichment factor of 2500 for all the target compounds (sample volume, $250 \mathrm{~mL}$ to $0.1 \mathrm{~mL}$ ). The obtained MDL and MQL fulfill with all $\mathrm{N}$-nitrosamines guideline regulations (stringent or less stringent) and with the provisional standard values considered in some European Countries.

Moreover, further research is needed to verify the applicability of the proposed analytical strategy for the analysis of wastewater samples. For such samples the main analytical limitation is related to the relatively high organic matter concentrations and as consequence, to the matrix effect. Thus, in this case it is necessary to evaluate if there is alteration in the extraction recoveries, elution profile or symmetry peak loss by matrix effect, in order to prove if the developed method is appropriate for the analysis $\mathrm{N}$-nitrosamines in this kind of water samples. Furthermore, future research should focus to confirm the use of the proposed analytical method for the detection of target molecules during the disinfection water process and in swimming pool waters. 
1 3.4. Application of the proposed method for the determination of pollution level in real

\section{water samples}

The applicability of the developed analytical method was assessed through the analysis of several surface water and tap water samples collected from different rivers and locations, in Brittany region (France), during different periods (summer and winter 2014 and summer 2015).

Samples were all extracted and analyzed under the optimized analytical (SPEUHPLC/MS/MS) conditions in 6 replicates $(n=6)$ according to the procedure described above. Quality standards were used as controls. It should be noticed that, for the sampling periods trip blanks are also carried out. The obtained data showed that the trip blanks are free of detectable target molecules.

The concentration of each N-nitrosamines determined in the collected samples are listed in Table 7.

\section{Table 7}

Data analysis showed that all target molecules were detected at least one time in collected water samples (surface and tap water). For all of them, the measured concentrations were in the range of nanogram per liter. As expected, the NDMA was most frequently detected. For the samples collected in summer the detected concentrations did not exceed $0.32 \mathrm{ng} \mathrm{L}^{-1}$. In winter, the highest detected concentration was $0.67 \mathrm{ng} \mathrm{L}^{-1}$. According to literature data, NDMA is the one of the N-nitrosamines which is most frequently detected in raw waters (Planas et al., 2008; Zhao et al., 2008). MNEA was detected in one river water sample (sample 5) collected in June-July and in October-November 2014, and the measured concentrations were 0.43 and $0.59 \mathrm{ng} \mathrm{L}^{-1}$, respectively. However, in this river samples the other nitrosamines were not detected, suggesting that the nitrosamine contamination depends on the location and source of water. These concentrations are much lower than the ones reported by Kim et al. (2013) for NMEA, in Korea, in Nakdong river (in the range 6.2 to 17.7 $\left.n g \mathrm{~L}^{-1}\right)$.

NDPA was only found in two of the six analyzed samples collected in OctoberNovember 2014. However, in June-July 2014 this molecule was found only in sample 3. For NDPA, the measured concentrations were in the range of 0.35 to $0.81 \mathrm{ng} \mathrm{L}^{-1}$. The study 
conducted by Kim et al. (2013) reported also the presence of NDPA in Nakdong river (Korea) at concentrations up to $455.4 \mathrm{ng} \mathrm{L}^{-1}$.

NMOR was only found in sample 6 with a concentration of $0.17 \mathrm{ng} \mathrm{L}^{-1}$. Templeton and Chen (2010), Zhao et al. (2008) also detected this N-nitrosamine in raw water samples.

Among the all considered $\mathrm{N}$-nitrosamines, in the analyzed tap water samples only, NDMA was detected in one of the six samples, at a very low concentration $\left(0.4 \mathrm{ng} \mathrm{L}^{-1}\right)$. Although the molecule was found in tap water, the detected concentration is lower that the California's notification level $\left(10 \mathrm{ng} \mathrm{L}^{-1}\right)$ or the Ontario's acceptable limit $\left(9 \mathrm{ng} \mathrm{L}^{-1}\right)$ (Kadmi et al., 2015a). Li et al. (2015), in a survey study of distribution of N-nitrosamines in drinking waters of east of China found NDMA with the highest detection frequency (31\%). Zhao et al. (2006), in a monitoring study reported for NDMA higher concentrations between 51.7 and $108.2 \mathrm{ng} \mathrm{L}^{-1}$. More recently, Rusell et al. (2012), regarded this molecule as the most prevalent $\mathrm{N}$-nitrosamine in drinking water.

NMEA and NDPA were only found in one of the six analyzed tap water samples (sample 5 and sample 3 , respectively). The found values are quite similar to the one measured for the NDMA.

The analysis of the presented data clearly showed that, in most of the analyzed water samples these molecules are not detected or present at concentrations levels below the detection limits of the developed method. The selected N-nitrosamines were found only in few of the collected samples at concentration levels much lower than those fixed by different international organizations and regulatory authorities.

While the NDMA was the N-nitrosamine most frequently found in this work, in near future, it is clear that this family of nitrogenous pollutants of health concern may come under increasing scrutiny as water contaminants and disinfection by-products.

\section{Conclusion}

In this paper, a suitable SPE-UHPLC/MS/MS analytical methodology for the analysis of N-nitroso compounds of health concern was developed. The proposed procedure enables the simultaneous extraction, pre-concentration and quantification of N-nitroso-n-propylamine, $\mathrm{N}$-nitrosomorpholine, N-nitrosomethylethylamine and $\mathrm{N}$-nitrosodimethylamine in various water samples (drinking and surface waters). The presented data clearly demonstrated that, the developed SPE-UHPLC/MS/MS method is highly sensitive and selective for their analysis 
1 at ultra-trace levels (few ng $\mathrm{L}^{-1}$ ). The analysis of the considered N-nitrosamines was 2 performed in $3 \mathrm{~min}$.

Good linearity, precision, accuracy, lower limits of detection, and quantification were 4 obtained for all target molecules. The Sep-Pak ${ }^{\circledR}$ AC-2 cartridges used for analytes extraction 5 from water samples led to satisfactory extraction recoveries and to high pre-concentration 6 factors of 2500. In addition, no significant matrix effect for the considered N-nitrosamines 7 was observed in surface water samples. Moreover, the developed analytical technique 8 provides low MDLs allowing the quantification of $\mathrm{N}$-nitrosamines at concentration levels 9 below the ones determined by many monitoring programs or below the notification levels established by different legislations. The excellent detection limits of the developed method make ultra-trace N-nitrosamine analysis possible.

In addition, the proposed method was successfully applied for the analysis of these molecules in real water samples and was shown to be convenient and reliable for their analysis in surface and tap water samples. The developed procedure is certainly, a powerful analytical tool for future toxicological, epidemiological and screening studies for the investigation of water pollution. It permits to rapidly initiate specific actions to minimize their environmental release or impact.

The application of the proposed method to the analysis of surface and drinking water samples from Brittany region (France) revealed that the selected N-nitrosamines were determined only in few of the collected samples, at concentration levels much lower than those fixed by different international organizations and regulatory authorities. Research is ongoing in order to have a more detailed evaluation of the pollution levels of N-nitrosamines associated with surface and drinking water in Brittany region in order to provide a more adequate spatial and temporal coverage.

\section{References} (NDMA) formation during ozonation of dimethylamine-containing waters. Water Res. 42, 863-870. 
1 Antignac, J.P., de Wasch, K., Monteau, F., De Brabander, H., Andrea, F., Le Bizec, B., 2005.

2 The ion suppression phenomenon in liquid chromatography• mass spectrometry and its

3 consequences in the field of residue analysis. Anal. Chim. Acta 529, 129-136.

4

5 Asami, M., Oya, M., Kosaka, K., 2009. A nationwide survey of NDMA in raw and drinking

6 water in Japan. Sci. Total Environ. 407, 3540-3545.

7

8 Bijlsma, L., Sancho, J.V., Pitarch, E., Ibáñez, M., Hérnandez, F., 2009. Simultaneous ultra-

9 high-pressure liquid chromatography-tandem mass spectrometry determination of

10 amphetamine and amphetamine-like stimulants, cocaine and its metabolites, and a cannabis

11 metabolite in surface water and urban wastewater. J. Chrom. A 1216, 3078-3089.

13 Caban, M., Migowska, N., Stepnowski, P., Kwiatkowski, M., Kumirska, J., 2012. Matrix 14 effects and recovery calculations in analyses of pharmaceuticals based on the determination of

- blockersand • •agonists in environmental samples. J. Chrom. A 1258, 117• 227.

Cha, W., Fox, P., Nalinakumari, B., 2006. High-performance liquid chromatography with fluorescence detection for aqueous analysis of nanogram-level N-nitrosodimethylamine. Anal. Chim. Acta 566, 109-116.

Chambers, E., Wagrowski-Diehl, D.M., Lu, Z., Mazzeo, J.R., 2007. Systematic and comprehensive strategy for reducing matrix effects in LC/MS/MS analyses. J. Chrom. B 852, 22-34.

Charrois, J.W.A., Arend, M.W, Froese, K.F., Hrudey, S.E., 2004. Detecting N-nitrosamines in drinking water at nanogram per litter levels using ammonia positive chemical ionization. Environ. Sci. Technol. 38, 4835-4841.

Cheng, R.C., Hwang, C.J., Andrews-Tate, C., Guo, Y., Carr, S., Sufflet, I.H., 2006. 
1 Cheng, X., Shi, H., Adams, C., Timmons, T., Ma, Y., 2011. Removal Study of N-

2 Nitrosamines by Powdered Activated Carbon in Natural and Reagent Water using SPE-

3 LC/MS/MS. Global J. Anal. Chem. 2, 232-240.

4

5 Commission Decision 2002/657/EC of 12 August 2002, 2002. Implementing Council

6 Directive 96/23/EC Brussels, Official Journal of the European Communities, L221 (August)

78.

8

9 Grebel, J.E., Young, C.C., Suffet, I.H., 2006. Solid-phase microextraction of N-nitrosamines.

J. Chrom. A 1117, 11-18.

11 Guerra Simões, N., Vale Cardoso, V., Ferreira, E., João Benolield, M., Almeida, C.M.M., 12 2007. Experimental and statistical validation of SPME-GC-MS analysis of phenol and 13 chlorophenols in raw and treated water. Chemosphere 68, 501-510.

14 Huang, M.C., Chen, H.C., Fu, S.C., Ding, W.H., 2013. Determination of volatile Nnitrosamines in meat products by microwave-assisted extraction coupled with dispersive micro solid-phase extraction and gas chromatography-chemical ionisation mass spectrometry. Food Chem. 138, 227-233.

Hung, H.W., Lin, T.F., Chiu, C.H., Chang, Y.C, Hsieh, T.Y., 2010. Trace analysis of Nnitrosamines in water using solid-phase micro-extraction coupled with gas chromatographytandem mass spectrometry. Water Air Soil Poll. 213, 459-469.

Jurado-Sánchez, B., Ballesteros, E., Gallego, M., 2009. Comparison of several solid-phase extraction sorbents for continuous determination of amines in water by gas chromatographymass spectrometry. Talanta 79, 613-620.

Kadmi, Y., Favier, L., Mouni, L., Nasrallah, N., Wolbert, D., 2014. A highly sensitive liquid chromatography-tandem mass spectrometry method for the analysis of a toxic water disinfection by-product, N-nitrosomethylethylamine. Anal. Methods 6, 3231-3234.

Kadmi, Y., Favier, L., Wolbert, D., 2015a. N-nitrosamines, emerging disinfection by-products of health concern: an overview of occurrence, mechanisms of formation and analysis in water. Water Sci. Technol. 15, 11-25. 
1 Kadmi, Y., Favier, L., Harja, M., Simion, A.I., Rusu, L., Wolbert, D., 2015b. A new strategy

2 for pentachlorophenol monitoring in water samples using ultra-high performance liquid

3 chromatography-tandem mass spectrometry. Environ. Eng. Manag. J. 14, 567-574.

4

5 Kadmi, Y., Favier, L., Simion, A.I., Wolbert, D., 2015c. A rapid and sensitive method for the

6 monitoring of N-nitrosodyphenylamine and N-nitrosodimethylamine in multiple water

7 matices. Carpath. J. Earth Env. 1, 53-61.

8

9 Kadmi, Y., Favier, L., Simion, A. I., Matei, E., Wolbert, D. (2016). Improved determination of dichloroacetic and trichloroacetic acids in water by solid phase extraction followed by ultra-high performance liquid chromatography tandem mass spectrometry. Anal. Lett. 49, 433-443.

Kim, G.A., Son, H.J., Kim, C.W., Kim, S.H., 2013. Nitrosamine occurrence at Korean surface water using analytical method based on GC/LRMS. Environ. Monit. Assess. 185, 1657-1669. river waters of the upper Tone River basin in Japan. Water Sci. Technol. 62, 2550-2557.

Krauss, M., Longrée, P., Dorusch, F., Ort, C., Hollender, J., 2009. Occurrence and removal of $\mathrm{N}$-nitrosamines in wastewater treatment plants, Water Res. 43, 4381-4391.

Li, T., Yu, D., Xian, Q., Li, A., Sun, C., 2015. Variation of levels and distribution of Nnitrosamines in different seasons in drinking waters of east China. Environ. Sci. Pollut. Res. 22, 11792-11800.

Llop, A., Borrull F., Pocurull E., 2012. Pressurized hot water extraction followed by headspace solid-phase microextraction and gas chromatography-tandem mass spectrometry for determination of N-nitrosamines in sewage sludge. Talanta 88, 284-289.

Matuszewski, B.K., Constanzer, M.L, Chavez-Eng, C.M., 2003. Strategies for the assessement of matrix effect in quantitative bioanalytical methods based on HPLC-MS/MS. Anal. Chem. 75, 3019-3030. 
1 McDonald, J.A., Harden, N.B., Nghiem, L.D., Khan, S.J., 2012. Analysis of N-nitrosamines

2 in water by isotope dilution gas chromatography-electron ionisation tandem mass 3 spectrometry. Talanta. 99, 146-154.

4 Mitch, W.A., Sharp, J.O., Trussell, R.R., Valentine, R.L., Alvarez-Cohen, L., Sedlak, D.L., 5 2003. N-nitrosodimethylamine (NDMA) as a drinking water contaminant: a review. Environ. 6 Eng. Sci. 20, 389-404.

7 Mourão Rodrigues, A., Ferreira, V., Vale Cardoso ,V., Ferreira, E., João Benoliel, M., 2007. 8 Determination of several pesticides in water by solid-phase extraction, liquid chromatography 9 and electrospray tandem mass spectrometry. J. Chrom. A 1150, 267-278.

Oya, M., Kosaka, K., Asami, M., Kunikane, S., 2008. Formation of N-nitrosodimethylamine (NDMA) by ozonation of dyes and related compounds. Chemosphere 73, 1724-1730.

Perez, D.M., Alatorre, G.G., Alvarez, E.B., Silva, E.E., Alvarado J.F.D., 2008. Solid-phase extraction of N-nitrosodymethylamine in beer. Food Chem. 107, 1348-1352.

Pepich, B.V., Domino, M.M, Dattilio, T.A., Fair, P.S., Munch., D.J., 2004. Validating sample preservation techniques and holding times for the approved compliance monitoring methods for haloacetic acids under the US EPA's stage 1 D/DBP rule. Water Res. 38, 895-902.

Planas, C., Palacios, Ã.S., Ventura, F., Rivera, J., Caixach, J., 2008. Analysis of nitrosamines in water by automated SPE and isotope dilution GC/HRMS: occurrence in the different steps of a drinking water treatment plant, and in chlorinated samples from a reservoir and a sewage treatment plant effluent. Talanta 76, 906-913.

Plumlee, M.H., López-Mesas, M., Heidlberger, A., Ishida, K.P., Reinhard, M., 2008. Nnitrosodimethylamine (NDMA) removal by reverse osmosis and UV treatment and analysis via $\mathrm{LC} / \mathrm{MS} / \mathrm{MS}$. Water Res. 42, 347-355.

Reyes-Contreras, C., Domínguez, C., Bayona, J. M., 2012. Determination of nitrosamines and caffeine metabolites in wastewaters using gas chromatography mass spectrometry and ionic liquid stationary phases. J. Chromatogr. A. 1261, 164-170. 
1 Richardson, S.D., 2009. Water analysis: emerging contaminants and current issues. Anal.

2 Chem. 81, 4645-4677.

3

4 Russell, C.G., Blute, N.K., Via, S., Wu, X., Chowdhury, Z., 2012. Nationwide assessment of 5 nitrosamine occurrence and trends. Journal AWWA 104, 205-217.

6

7 Schreiber, I.M., Mitch, W.A., 2005. Influence of the order of reagent addition on NDMA

8 formation during chloramination. Environ. Sci. Technol. 39, 3811-3818.

Sedlak, D.L., Deeb, R.A., Hawley, E. L., Mitch, W.A., Durbin, T. D., Mowbray, S., Carr, S., 2005. Sources and fate of nitrosodimethylamine and its precursors in municipal wastewater treatment plants. Water Environ. Res. 77, 32-39.

Taguchi, Y.V., Jenkins, D.S.W., Wang, T.D., Palmentier, P.J.P.F., Reiner, J.E., 1994.

Determination of N-nitrosodimethylamine by isotope dilution, high-resolution mass spectrometry. Can. J. App. Spectrosc. 39, 87-93.

Templeton, M., Chen, Z., 2010. NDMA and seven other nitrosamines in selected UK drinking water supply systems. J. Water Supply Res. T. 45, 277-283.

Topuz, E., Aydin, E., Pehlivanoglu-Mantas, E., 2012. A practical LC-MS/MS method for the detection of NDMA at nanogram per liter concentrations in multiple water matrices. Water Air Soil Poll. 223, 5793-5802.

Van Eeckhaut, A., Lanckmans, K., Sarre, S., Smolders, I., Michotte, Y., 2009. Validation of bioanalytical LC-MS/MS assays: Evaluation of matrix effects. J. Chrom. B 877, 2198-2207.

Ventanas, S., Ruiz, J., 2006. On-site analysis of volatile nitrosamines in food model systems by solid-phase microextraction coupled to a direct extraction device. Talanta 70, 1017-1023.

World Health Organization (WHO), 2011. Guidelines for Drinking Water Quality, N- 
1 Zhao, Y.Y., Boyd, J., Hrudey, S.E., Li, X.F., 2006. Characterization of new nitrosamines in

2 drinking water using liquid chromatography tandem mass spectrometry. Environ. Sci.

3 Technol. 40, 7636-7641.

4

5 Zhao, Y.Y., Boyd, J.M., Woodbeck, M., Andrews, R.C., Qin, F., Hrudey, S.E., Li, X.F., 2008.

6 Formation of N-nitrosamines from eleven disinfection treatments of seven different surface

7 waters. Environ. Sci. Technol. 42, 4857-4862.

8

9

10

11

12

13

14

Figure captions

15

16

Figure 1. Water sampling locations on the Brittany territory considered in this study.

17

18

19

20

21

22

23 
Table 1. Physico-chemical properties and toxicity of the considered N-nitrosamines.

\begin{tabular}{|c|c|c|c|c|c|}
\hline $\begin{array}{c}\text { Nitrosamines } \\
\text { (Abbr.) }\end{array}$ & $\begin{array}{l}\text { Molecular } \\
\text { formula }\end{array}$ & $\begin{array}{l}\text { Molecular } \\
\text { weight } \\
\left(\mathrm{g}^{\cdot} \mathrm{mol}^{-1}\right)\end{array}$ & $\log K_{0 / w}$ & $\begin{array}{c}\text { Water } \\
\text { solubility } \\
\left(\mathrm{mg}^{\cdot} \mathbf{L}^{-1}\right)\end{array}$ & $\begin{array}{l}\text { Standard U.S. EPA* } \\
\text { cancer classification } \\
\text { group }\end{array}$ \\
\hline NDMA & $\mathrm{C}_{2} \mathrm{H}_{6} \mathrm{~N}_{2} \mathrm{O}$ & 74.082 & -0.57 & $1,000,000$ & B2 \\
\hline NMEA & $\mathrm{C}_{3} \mathrm{H}_{8} \mathrm{~N}_{2} \mathrm{O}$ & 88.108 & 0.04 & 300,000 & B2 \\
\hline NDPA & $\mathrm{C}_{6} \mathrm{H}_{14} \mathrm{~N}_{2} \mathrm{O}$ & 130.188 & 1.36 & 13,000 & B2 \\
\hline NMOR & $\mathrm{C}_{4} \mathrm{H}_{8} \mathrm{~N}_{2} \mathrm{O}_{2}$ & 116.059 & -0.44 & $861,527.5$ & $2 \mathrm{~B}(\mathrm{IARC}) * *$ \\
\hline
\end{tabular}

*United States Environmental Protection Agency

**IARC: International Agency for Research on Cancer 
Table 2. Optimized MS/MS parameters.

\begin{tabular}{lc}
\hline Parameter & Value \\
\hline Source temperature $\left({ }^{\circ} \mathrm{C}\right)$ & 120 \\
Capillary voltage $(\mathrm{kV})$ & 3.0 \\
Desolvation temperature $\left({ }^{\circ} \mathrm{C}\right)$ & 350 \\
Desolvation gas flow $\left(\mathrm{L} \mathrm{h}^{-1}\right)$ & 750 \\
Cone gas flow $\left(\mathrm{L} \mathrm{h}^{-1}\right)$ & 75 \\
\hline
\end{tabular}

Table 3. Ionization mode, MRM transitions used for quantification and confirmation purposes and optimized values used for cone voltage and collision energy for the analysis of $\mathrm{N}$ nitrosamines.

\begin{tabular}{cccccc}
\hline Analyte & $\begin{array}{c}\text { Ionization } \\
\text { mode }\end{array}$ & $\begin{array}{c}\text { Transition of } \\
\text { quantification } \\
\end{array}$ & $\begin{array}{c}\text { Transition of } \\
\text { confirmation }\end{array}$ & $\begin{array}{c}\text { Cone } \\
\text { voltage }\end{array}$ & $\begin{array}{c}\text { Collision } \\
\text { energy }\end{array}$ \\
& & $(\mathbf{m} / \mathbf{z})$ & $(\mathbf{V})$ & $(\mathbf{e V})$ \\
\hline NDMA & & $74.7>42.8$ & $75.0>58.5$ & 25 & 10 \\
NMEA & ESI $^{+}$ & $88.7>60.7$ & $88.7>42.8$ & 25 & 10 \\
NDPA & & $131.5>43.8$ & $130.8>88.6$ & 22 & 11 \\
NMOR & & $116.9>86.2$ & $116.9>41.7$ & 28 & 10 \\
\hline
\end{tabular}


Table 4. Extraction recoveries (\%) and relative standard deviation (RSD, \%) obtained with the proposed SPE methodology for each analyte in ultrapure water for different spiking levels.

\begin{tabular}{cccc}
\hline Analyte & $\begin{array}{c}\text { Conc. } \text { spiked } \\
\left(\mathbf{n g ~ ~ L ^ { - 1 } )}\right.\end{array}$ & $\begin{array}{c}\text { Conc. } \text { measured } \\
\left(\mathbf{n g ~ ~ ^ { - 1 }}\right)\end{array}$ & Recovery (\%) \pm RSD (\%, $\mathbf{n}=\mathbf{6})$ \\
\hline \multirow{3}{*}{ NDMA } & 0.40 & 0.39 & $98 \pm 1$ \\
& 4.00 & 3.92 & $98 \pm 1$ \\
& 40.0 & 39.33 & $98 \pm 1$ \\
\hline \multirow{3}{*}{ NMEA } & 0.40 & 0.39 & $99 \pm 1$ \\
& 4.00 & 3.97 & $99 \pm 1$ \\
& 40.0 & 39.75 & $99 \pm 1$ \\
\hline \multirow{3}{*}{ NDPA } & 0.40 & 0.39 & $98 \pm 2$ \\
& 4.00 & 3.94 & $99 \pm 1$ \\
& 40.0 & 39.46 & $99 \pm 1$ \\
\hline \multirow{3}{*}{ NMOR } & 0.40 & 0.40 & $100 \pm 1$ \\
& 4.00 & 4.00 & $100 \pm 1$ \\
& 40.0 & 40.0 & $100 \pm 1$ \\
\hline
\end{tabular}


Table 5. Regression coefficients $\left(\mathrm{R}^{2}\right)$ for the instrumental and sample calibration curves, matrix effects and relative standard deviation (RSD) of the selected $\mathrm{N}$-nitrosamines spiked at $0.4 \mathrm{ng} \mathrm{L}^{-1}$.

\begin{tabular}{cccc}
\hline Analyte & $\begin{array}{c}\mathbf{I C C}^{\mathbf{a}} \\
\left.\mathbf{( R}^{\mathbf{2}}\right)\end{array}$ & $\begin{array}{c}\mathbf{S C C} \\
\mathbf{( R}^{\mathbf{2}}\end{array}$ & Matrix effect $\mathbf{( \% )} \pm \mathbf{R S D}(\mathbf{\%}, \mathbf{n}=\mathbf{6})$ \\
\hline NDMA & 0.9987 & 0.9962 & $98 \pm 2$ \\
NMEA & 0.9991 & 0.9983 & $99 \pm 2$ \\
NDPA & 0.9995 & 0.9978 & $98 \pm 2$ \\
NMOR & 0.9992 & 0.9961 & $100 \pm 1$ \\
\hline
\end{tabular}

${ }^{\text {a }}$ Instrument calibration curve

${ }^{\mathrm{b}}$ Sample calibration curve

Table 6. Instrumental detection limit (IDL), instrumental quantification limit (IQL), concentration factor (FC) of the extraction method and method limit of detection (MDL) and method quantification limit of quantification (MQL).

\begin{tabular}{|c|c|c|c|c|c|}
\hline Analyte & $\begin{array}{c}\text { IDL } \\
\left(\mu g L^{-1}\right)\end{array}$ & $\begin{array}{c}\text { IQL } \\
\left(\mu g \mathrm{~L}^{-1}\right)\end{array}$ & $\overline{\text { FC }}$ & $\begin{array}{c}\text { MDL } \\
\left(n g L^{-1}\right)\end{array}$ & $\begin{array}{c}\text { MQL } \\
\left(\mathrm{ng} \mathrm{L}^{-1}\right)\end{array}$ \\
\hline NDMA & 0.25 & 1.50 & \multirow{4}{*}{2500} & 0.10 & 0.60 \\
\hline NMEA & 0.50 & 2.00 & & 0.20 & 0.80 \\
\hline NDPA & 1.00 & 3.00 & & 0.40 & 1.20 \\
\hline NMOR & 0.10 & 0.25 & & 0.04 & 0.10 \\
\hline
\end{tabular}


Table 7. Maximal concentrations (ng $\mathrm{L}^{-1}$ ) measured in surface and tap water samples.

\begin{tabular}{|c|c|c|c|c|}
\hline \multirow{2}{*}{ Sampling point } & \multicolumn{4}{|c|}{ N-nitrosamines detected $\left(\mathrm{ng} \mathrm{L}^{-1}\right) \pm \operatorname{RSD}(\%),(n=6)^{b}$} \\
\hline & NDMA & NMEA & NDPA & NMOR \\
\hline \multicolumn{5}{|c|}{$\begin{array}{c}\text { Summer } \\
\text { (June-July 2014) }\end{array}$} \\
\hline River water 1 & $0.2 \pm 0.1$ & $\mathrm{ND}^{\mathrm{a}}$ & $<\mathrm{LD}$ & ND \\
\hline River water 2 & $\mathrm{ND}^{\mathrm{a}}$ & ND & $\mathrm{ND}$ & ND \\
\hline River water 3 & $<\mathrm{LD}^{\mathrm{b}}$ & ND & $0.6 \pm 0.3$ & $<\mathrm{LD}$ \\
\hline River water 4 & ND & ND & $\mathrm{ND}$ & $\mathrm{ND}$ \\
\hline River water 5 & ND & $0.4 \pm 0.3$ & ND & ND \\
\hline River water 6 & $0.3 \pm 0.3$ & ND & ND & $<\mathrm{LD}$ \\
\hline \multicolumn{5}{|c|}{$\begin{array}{c}\text { Winter } \\
\text { (October-November 2014) }\end{array}$} \\
\hline River water 1 & $\mathrm{ND}^{\mathrm{a}}$ & ND & $0.4 \pm 0.2$ & ND \\
\hline River water 2 & $<\mathrm{LD}$ & ND & ND & $<\mathrm{LD}$ \\
\hline River water 3 & $0.4 \pm 0.2$ & ND & $0.8 \pm 0.4$ & ND \\
\hline River water 4 & $0.2 \pm 0.2$ & ND & ND & ND \\
\hline River water 5 & ND & $0.6 \pm 0.2$ & $<\mathrm{LD}$ & ND \\
\hline River water 6 & $0.7 \pm 0.5$ & ND & ND & $0.2 \pm 0.1$ \\
\hline
\end{tabular}

\section{Summer}

(June-July 2015)

\begin{tabular}{lcccc}
\hline Tap water 1 & $<\mathrm{LD}$ & $\mathrm{ND}^{\mathrm{a}}$ & $<\mathrm{LD}$ & $\mathrm{ND}$ \\
Tap water 2 & $\mathrm{ND}$ & $\mathrm{ND}$ & $\mathrm{ND}$ & $\mathrm{ND}$ \\
Tap water 3 & $<\mathrm{LD}$ & $\mathrm{ND}$ & $<\mathrm{LD}$ & $\mathrm{ND}$ \\
Tap water 4 & $\mathrm{ND}$ & $\mathrm{ND}$ & $\mathrm{ND}$ & $<\mathrm{LD}$ \\
Tap water 5 & $\mathrm{ND}$ & $<\mathrm{LD}$ & $\mathrm{ND}$ & $\mathrm{ND}$ \\
Tap water 6 & $0.4 \pm 0.2$ & $\mathrm{ND}$ & $\mathrm{ND}$ & $<\mathrm{LD}$ \\
\hline
\end{tabular}

${ }^{\mathrm{a}} \mathrm{NF}$ : not found

${ }^{\mathrm{b}} \mathrm{LD}$ : limit of detection 


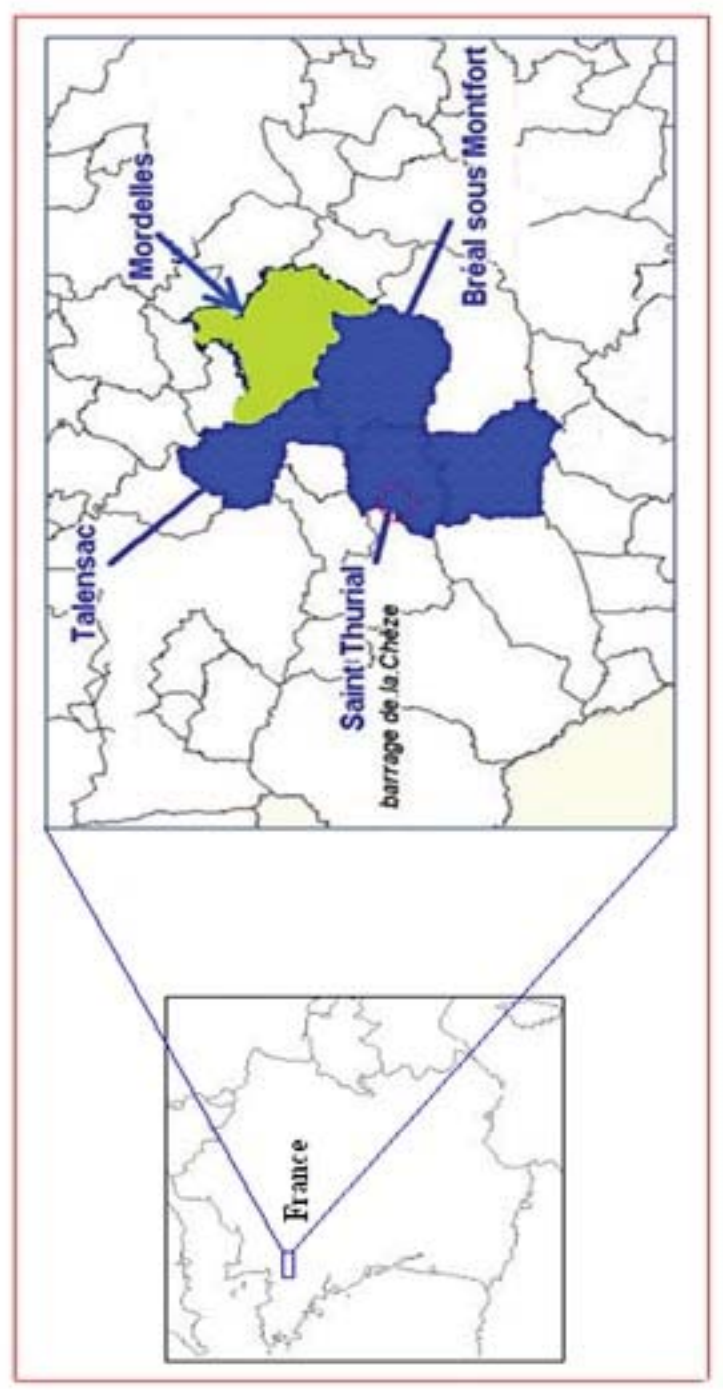

